\title{
Retrospective Meta-Analysis on the Random and Homogeneous Effects of the Validity of the Risk Perception Scale
}

\author{
Margarita Juàrez-Nàjera*, Jorge Hernàndez-Valdès, Gilberto Bermùdez-Ruìz, Francisco Espinoza-Morales, Cruz Garcìa-Lirios \\ Department Engineering, UAM, Mèxico.
}

*Corresponding Author: Margarita Juárez-Nàjera, Department Engineering, UAM, Mèxico.

Received date: September 04, 2021; Accepted date: October 05, 2021; Published date: October 11, 2021

Citation: Margarita Juàrez-Nàjera, Jorge Hernàndez-Valdès, Gilberto Bermùdez-Ruìz, Francisco Espinoza-Morales, Cruz Garcìa-Lirios (2021) Retrospective Meta-Analysis on the Random and Homogeneous Effects of the Validity of the Risk Perception Scale. J. Archives of Medical Case Reports and Case Study, 4(6); DOI:10.31579/2692-9392/074

Copyright: (C) 2021 Margarita Juárez-Nàjera, This is an open access article distributed under the Creative Commons Attribution License, which permits unrestricted use, distribution, and reproduction in any medium, provided the original work is properly cited.

\begin{abstract}
:
Objective: of this study was to carry out a systematic review of the literature to reveal the policies of metropolitan mobility and peri-urban health, focusing the discussion on the effects of public transport safety on the health of users.

Methodology: A documentary, retrospective and meta-analytic study was carried out with a non-probabilistic selection of indexed sources published from 2010 to 2020 and search with the key words.

Results: Prevalence of data that sustain the non-exposure to risk events derived from mobility policies in public transport safety and the health of users.

Discussion: Political comparisons reveal the prevention of the effects of risk events on the health of users.

Conclusion: Mobility policies, focused on the effects of transport safety on the health of users, do not recognize the risks of exposure or the short, medium and long-term consequences.

Keywords: mobility; public transport; security; meta-analysis; governance
\end{abstract}

\section{Introduction}

The safety of crime in public transport suggests the implementation of policies, strategies and programs for the prevention of crime and prosecution of risk events that could be exacerbated by negligence, corruption, nepotism, opacity or incompetence of the authorities as guarantors of the civil protection [1].

In the context of crime safety in public transport, the state has generated public opinion currents that legitimize its administration in the management and administration of public mobility through investments in video systems: security, training of specialized police or programs, checkpoints and assistance in tolls, cabins, federal roads and bridges [2].

However, robberies, kidnappings, accidents and aggressions against users have generated a counter propaganda that not only discredits the rector of the State, but also replaces it with a system of citizen self-management that consists of the prevention of crime through the dissemination of alleged criminals, routes of fear or police corruption, as well as the systematic denunciation through testimonies and video recordings before the media, while self-defense actions such as the capture of delinquents or lynching's are gestated [3].
The Metropolitan Area of the Valley of Mexico is concentrated in most of the public transport, but only in Mexico City $80 \%$ for $45 \%$ of users and $55 \%$ mobilize in motor transport. In contrast, the State of Mexico, located around Mexico City, concentrates 20\% of public transportation for 55\% of its inhabitants in Mexico City [4]. This is an imbalance that translates into the state of Mexico and Mexico City. In this way, Mexico City receives around one million 735 thousand workers and students from the State of Mexico (one million 676 thousand), Hidalgo (28 thousand), Morelos (14 thousand) and Puebla (15 thousand). However, the complaints regarding insecurity have decreased. In 2012, 2441 complaints were lodged, but in 2018 only 1564 were processed [5].

In Metropolitan Zone of the Valle México (ZMVM) about 45\% of the vehicle fleet shuttle is the public transport private car followed with $29 \%$ and taxi use $11 \%$. Inflation (4\% accumulated during 2013) of gasoline has increased by $40 \%$, premium by $30 \%$, diesel by $48 \%$, while salary only increased by $28 \%$ [6].

Mexico City occupies the last places in terms of pedestrian movement with a figure of around $2 \%$, followed by New York City with $10 \%$ and the City of London with $20 \%$ while in the city of Bombay $55 \%$ of the deployments are on foot [7]. 
About the family economy, transportation expenses are divided into 50\% for buses or minibuses, $30 \%$ for urban buses, $16 \%$ for radio taxis and $2 \%$ for metro. In this context, it is possible to notice that the sustainability of public transport implies the establishment of a collection system according to peri-urban mobility capacities [8].

In 2012 there were around 580 robberies that by 2015 had increased to 600 thousand assaults in public, private and concessioned transport. In the cases by demarcation, $22 \%$ of the cases were registered in the Coyoacán delegation, followed by Gustavo A. Madero with $15 \%$ of the cases, Iztapalapa with $14 \%$ and Venustiano Carranza with $12 \%$ of the crimes $\{9\}$.

However, public transportation of cities in Mexico is considered unsafe. It is estimated that in the last eight years around $20 \%$ of users have stopped transporting in the public system, considering it highly dangerous in Mexico City [10]. In 2011, 78\% of respondents said they felt unsafe in public transport and by 2015 they increased to $80 \%$ of respondents. In 2012, the minibus with 1394, followed by the taxi with 641 and the metro with 404 crimes were the scenarios of greatest insecurity. In 2015, 983 cases occurred in the minibus, 340 in the metro and 241 in taxis [11].

These data exemplify the volume of governance or coordination between political and civil actors, public and private sectors around security, even though statistics highlight the reduction of complaints, crimes seem to hide the discourses surrounding the problematic, since the reduction of complaints does not imply a reduction of crimes or a civil trust in the authorities [12].

Therefore, the aim of this paper is to carry out a meta-analysis of the literature related to safety or insecurity as a result of exposure or nonexposure of public transport users and their impact on their physical or emotional integrity registered in 2010 to 2020 [13].

From a meta-analytical approach, it will be possible to observe the effects of safety or insecurity on the health of users to adjust mobility policies and the public administration of the system, as well as citizen selfmanagement [14].

Unlike the public policies of public transport that emerge from the discretion of authorities and advisors, meta-analytic approaches allow to reveal the retrospective conditions of exposure or not to security or insecurity and its effects on the users of a system [15].

In the construction of an agenda on mobility in public transport, the metaanalytic approach suggests a systematic review of the literature that reports the effects of exposure or not of risk events such as accidents or diseases associated with crime, corruption, extortion, the negligence, opacity or nepotism of the authorities and whose effects are observed in the mental and physical health of the users [16].

In such a scenario of exposure to risk events such as earthquakes, fires, coalitions, floods or landslides exacerbated by government action or inaction, public insecurity is created whose effects on the health of users has been recorded in order to establish the conditions of relative risk and proportion of indispensable probabilities to build Metropolitan governance [17].

This is a scenario in which social diagnosis, civil protection and evaluation of such intervention are convenient. In virtue of which, the development of an integrative model of state management and social selfmanagement are indispensable to reach agreements between the parties involved [18].

The mediation of public policies and social needs suppose differences between political and social actors [19]. This is because the inclusion of citizens in the political sphere and the inclusion of rulers in civil affairs is increasingly necessary [20].
That is, a meta-analysis of the effects of risks in public transport on the health of users is a diagnostic that guides the strategies among civil society to achieve the sustainability of a system [21].

Metropolitan governance and its public agenda are geared towards sociostate co-management, affirming more similarities than differences between authorities and users of public transport, although the establishment of tariffs seems to be a pending issue between the government and citizens, since Subsidies will prevail to the extent that the quality of the service is low [22].

Despite the fact that safety and quality in public transport is an objective, a task and a common goal among political and social actors, the differences between the rates of the city center with respect to the periphery, as well as deregulation of transport, Discretionary concessions and the deterioration of public transport units affect the health of users and seem to show that there is an ungovernability and the impossibility of governance or management and administration agreed between civil society and the State [23].

\section{Theory of perception risk}

Literature consults, focuses its interest on the effects of public policies whose dimensions it places between acultural, multicultural, multicultural, intercultural and transcultural [24].

The reviewed publications suggest that the acultural, multicultural and multicultural policies are linked to the cases of exposure and nonexposure without health consequences, since they highlight the rector of the State and the efficient administration of the system, legitimizing increases to the public service without corresponding to the quality and safety of them [25].

The acultural policy is distinguished from the multicultural and multicultural to the native communities that inhabit the cities with respect to the migrant flows that go from the urban periphery to the urban centrality [26]. This is the case of availability, quality and transport subsidy, which in the centrality is two or three times greater than the cost, availability and quality of transport in the periphery [27].

The multicultural policy recognizes the arrival of migrant flows for labor or educational reasons but does not subscribe to these sectors and only guarantees its security with the video surveillance system that prevails in the urban centrality [28]. That is, it responds to complaints, but does not follow up on them or seek a comprehensive resolution to the problem, justifying its inaction due to the lack of complaints or endorsing its responsibility to individuals, promoting austerity so as not to attract the attention of the offender [29].

Multicultural policies on public transport highlight coexistence and order as central premises between migratory flows and native communities but adjusting the uses and customs of visitors to the laws of urban centrality [29]. In this way, a crime committed in a unit that goes from the periphery to the centrality is considered a responsibility of the federal rather than local authority [30]. Or, the demarcation of responsibility before the deregulation of transport in the urban periphery [31].

In contrast, public mobility policies from intercultural and transcultural approaches highlight the exposure and non-exposure of users to risk events derived from climate change and exacerbated by local corruption with short, medium and long-term sequels in mental health and physics of the users, reflecting in the distrust towards their authorities and the conflicts with the dependencies of government in charge of the management and administration of the system [32].

The intercultural policy seeks co-responsible administration between the government entities of centrality and periphery, preventing and imparting justice to crimes committed in the public transport system and assistance 
to victims of risk, corruption and crime, but considering a dialogue permanent relationship between government and education and labor sectors, syndicates and civil organizations for the improvement of the quality and security of the system [33].

Based on the increase in risk events and corruption, the cross-cultural policy seeks to reduce risks in public transport based on the elimination of administrative boundaries for decentralization and investment; generating opportunities for health, education and employment in the periphery; training employees and police, as well as promoting lives free of violence and risks to users [34].

Based on these distinctions, it is possible to notice that the literature seems to focus on the effects of multicultural and cross-cultural policies that recognize user exposure to risk and corruption, but do not know or recognize minimal sequelae in their mental and physical health, directing their speeches towards the subdistrict to attend to the well-being of the user [35].

\section{Studies of perception risk}

Studies related to public transport focus on the subjectivity of authorities and users when evaluating the quality and security of public resources and services from their perceptions.

Additional property are differences between users over conventional transport with reference to public transportation called sustainable [36]. They also foundsignificant differences between the uses of electricity optimization vehicles and hydrocarbons [37]. Regarding the perceptions of the genders regarding the tariffs and environmental impact of transport in general, they also found differences [38]. However, about high, medium and low incomes, the differences were confined to the use of bicycles, rickshaws, motorcycles and trolleys [39].

The findings found the research in which public transport was established as multidimensional due to its sociopolitical context and the daily use of university, has shown hypotheses concerning econcéntrics knowledge and its impact on the perceptual differences between men and women complement the above findings [40].

The differences that stand out in the studies regarding how public transport is considered show a central problem inherent to the user: the representation of its instrumentation for a sustainable local development [41].

It is known that the construction of a collective transport system arises from a female ethic of caring for the environment [42]. In contrast, masculinity considers the system and the environment instrumental for an end to comfort, but the meta-analysis emphasizes that such distinctions are exacerbated in an acultural political system [43].

This is the case of postmaterialism that studies of public transport highlight as an explanation to the relationship between intensive use and destination planning [44]. To the extent that users consider that the transport is a cost-effective instrument, they will plan their arrival at central, tourist, recreational or comfort-free places without considering the crowds, accidents or insecurity that the saturation of a transport system entails. Determined hours [45].

On the contrary, from public policies that consider public transport as a cultural heritage which should be conserved for future generations, the ethics of female care seems to emerge as a hallmark of the choice of destinations and the prevention of risks.

From an acultural policy, public transport is an instrument of entry and exit of workforce with a predetermined destination of production, service and consumption [46]. It is a classic perception that semi-rural periphery must be developed in an urban environment where services proliferate, and transport is distinguished by its efficiency of transfer to work and education nodes [47]. The ethic of care is more distinctive of this policy since it seeks the prevention of accidents and diseases that reduce the productivity of the workforce or strengthen the health system for the care due to diseases [48].

The policultural and multicultural initiatives that influence public transport seek to endow it with a positive experience; recreational and satisfactory for the comfort of the user who visits shopping centers or recreational nodes, appreciating the diversity of entertainment or recreation, as well as the assurance that their integrity will always be protected [49]. The ethics of care translates into the preservation of public spaces, central locations and public squares with the aim of promoting concord and pacification as a reward for the transfer of an unsafe scenario to a guarded site, but with freedom of expression and action [50]. The transportation system is also an instrument for inclusion of minorities that manifest themselves in public places and interact with other migratory, tourist and native flows [51].

The provisions for the use of public transportation that distinguish acultural, poly and multicultural policies contrast with intercultural and transcultural initiatives to regulate the activities of natives based on the rights of migrants or the work of minorities according to the requirements native [52]. The ethic of care is exacerbated by the availability of public transport and its nodes that are no longer distinguished by their origin or destination [53].

The hypothesis regarding social postmaterialism in which high incomes correspond to the use of sustainable rather than conventional transport seems to show that the habitus around the use of public transport is oriented by materialistic and therefore anthropocentric views rather than by habitus. ecocentric and postmaterialist [54].

The use, cost and impact of public transport in the university environment implies: Perceptions related to gender knowledge and perspectives that establish significant differences among users [55]. Therefore, the conventional public service compared to the so-called sustainable system, when considered asymmetric, explains the transition from environmental knowledge to environmental rationality [56].

However, a preponderant factor in the transition towards sustainability is postmaterialism [57]. The hypothesis of differences between economic income does not support the difference between perceptions regarding the use of sustainable transport in relation to the disuse of conventional and polluting transport [58]. In this way, the sustainability of public transport should be explained from the effect that transport policies have on user groups [59].

Studies of public transport will move towards lines related to metropolitan governance in order to generate programs and strategies for management or administration from the acultural, poly, multi, inter and transcultural approaches [60]. The corresponding public policies will not only prevent the differences between political and social actors, public and private sectors, but will also generate transport systems according to the needs of the users, not because of the image of transport or the representation of their destination, but rather the emergence of environmental care proposals [61].

This is the case of the helplessness or despair that distinguishes the urban centrality from the urban periphery [62]. It is an unfavorable disposition to the collective use and the subsidy with respect to the investment in the sector until achieving its sustainability and with it contributing to the conservation of the city [63].

\section{Method}

A documentary study was carried out with a selection of sources indexed to the main repositories of Latin America: Dialnet, Copernicus, Ebsco, 
Frontiers, Latindex, Publindex, Redalyc, Scielo, Scopus, WoS, Zenodo and Zotero considering the publication period from 2010. until 2020, as well as the keywords: "governance", "management", "self-management", "quality", "security", "administration", "mobility" and "transport" for the case of cities with risks documented in their public transport system and effects on users.

The information was codified, following the model as well as the decomposition considering: By virtue of the literature, I have focused your attention on risk events such as landslides, floods, hurricanes, fires, droughts, pollution, contingencies, crime, violence that caters or indirectly to the quality of public transport service and that can o They are not generated in the physical or mental health of the users, as well as in their opinion of the public administration, local or federal government, the types of literature are distinguished for an approach to the problem.

Literature type A for cases of exposure of users to risk events (floods, landslides, fires, coalitions, earthquakes) and exacerbation of the same by corruption (negligence, opacity, nepotism, extortion) with health effects (stress, helplessness, hyperopia, distrust)

Type B literature for cases of non-exposure to risk events and corruption, but with effects on health.

Literature type $\mathrm{C}$ for cases of exposure to risk and corruption events, but without effects on health.

Type D literature for cases of non-exposure to risk events and corruption, but without effects on health.

The meta-analysis technique is enough in terms of the parameters you can use to reach a conclusion. In the present work, considering that the problem alludes to the possible effects or not of risks in the public transport on the health of the users, the meta-analysis is understood as an instrument for the diagnosis of possible consequences for the use of public transport in users who may or may not be exposed to floods, fires, environmental contingencies, pollution, insecurity, violence and crime, associated with stress, exhaustion, depersonalization or frustration.

The information was processed in the statistical package for social sciences (SPSS version 23.0). The proportions of probability (OR) were estimated with a level of significance of $95 \%$

The OR parameter (odds ratio) is used in health sciences to communicate the results of a research, referring to a coefficient between two occurrence probabilities of an event in order to anticipate a relative risk (RR), although in retrospective designs the OR parameter is more used.

The RR estimates suppose confusion biases since they endorse the effect of different risks allusive to the observed events, being the estimation of adjusted OR more feasible since the weighting of adjusted RR cannot be carried out with the most commonly used technique as logistic regression, only binomial logarithmic models reduce confounding bias by providing RR and OR adjustment.

In this way, the formula to explain prospective and retrospective events is:

Prospective: $\mathrm{OR}=(\mathrm{a} / \mathrm{b})(\mathrm{c} / \mathrm{d})$; being $\mathrm{a}=$ exposed, $\mathrm{b}=$ intervened, $\mathrm{c}=$ not exposed and $\mathrm{d}=$ not intervened

Retrospective or unpaired cases and controls: $\mathrm{OR}=(\mathrm{a} / \mathrm{c})(\mathrm{b} / \mathrm{d})$ where a and c are the subjects' exposure to an event of interest, as well as c and d or exposure of the subjects without the event of interest. In both studies, as well as in cross-sectional studies, the confidence interval that suggests the degree of OR variability is fundamental.

Then, the information was processed in a matrix of content analysis with the purpose of extracting the main concepts of the security agenda in public transport and to establish hypotheses concerning the trajectories of the relationships between the selected concepts. Finally, the scope and limits of the model proposed in the framework of co-government between authorities and users were discussed.

From the literature of findings that relate or not the possible effects of risks in public transport with respect to the health of users with no sequelae, expert judges in the thematic areas rated the results in a Delphi questionnaire in three rounds of feedback from opinions.

The information was coded from the Delphi technique, which suggests the qualification of experts considering: 0 for literature that reports no exposure and no user involvement; 1 for the literature that reports the exhibition, but not affect; 2 for literature that warns of exposure and affectation; 3 for the report of exposure and affectation.

Once the first qualification round was made, the results were returned to the judges who adjusted their qualification criteria or maintained their position. In a third final round, the lower and higher scores of judges who maintained their position or modified it were eliminated, but they deviated from the consensus.

\section{Results}

The proportions of probability of occurrence of risk events and their possible effects on the health of users.

The associations between the types of policies and the types of literature allowed to carry out models to investigate their structural composition. Once the probabilities of relative risk were established around the risk events and their effects on the local health of public transport users, we proceeded to estimate their structure of relationship trajectories, considering the possible combinations between the types of policies and the types of literature.

It is possible to appreciate that the trajectories of reflective relationships between the types of policies and the types of literature suggest a moderate relative risk. That is, the literature seems to record different exposures or not to risk events with different effects or not to the health of the users, highlighting the allusive to non-exposure and non-impact that in the acultural policies are established as a metropolitan agenda.

With the purpose of observing the emergence of a common policy to the acultural, poly, multi, inter and transcultural policies, the estimation of a confirmatory structure was carried out

It is possible to observe the emergence of a health policy configured from the acultural, poly, multi, inter and transcultural perspectives, suggesting a dependency relationship between these elements that would explain the composition of the health policy in terms of attention to the effects of risk events in public transport and its effect on users' health during the period from 2010 to 2020 .

The relations between the types of policies and the types of literature allowed to carry out an analysis of relations of dependence between the elements

The structure of dependency relations between the types of policies and the types of literature show that the acultural policies, indicated by literature that reports the exposure or not of users of public transport in risk events and that had effects on their health or not, influenced local health policies, indicated by the four types of exposure and sequelae enunciated.

In order to observe the probability ratio structure, the ranges and probability of occurrence were established.

It is possible to see that there is a greater proportion of the probability that the principles of the cultural policy affect the local health policy. Next, the foundations of poly and multicultural politics would be influencing more than intercultural and transcultural presuppositions, suggesting that 
public transport is an instrument of management and risk management related to the effects of health events.

\section{Discussion}

The contribution of the present work to the state of the question lies in a meta-analysis of the contributions to the incidence of risk events associated with corruption on environmental public health, although the design of the research limits the findings to the local scenario, suggesting the extension of work to other metropolises in Latin America.

The technique of data meta-analysis allows glimpses of public transport as a contingent phenomenon that aggravates the risks and could reduce them whenever the metropolitan policies recognize exposure and with or without sequelae, as well as non-exposure and its minor effects or maximums in the health of the users.

However, risk events have highlighted their effects on environmental public health, the emergence of an environmental care ethic and have highlighted a collective response of users known as postmaterialism to explain the intensive use of transport no longer only for its image and destiny, but for the idea of considering that the economic welfare generates more needs of transfer and shelter.

The consequences of the impact of risk events and public policies on the health of users is not explicitly recognized in the acultural, multicultural and multicultural approach, but it is in the intercultural and transcultural approach where the symbolization of these sequelae in diseases prevails. , accidents or contingencies.

Lines of research related to metropolitan public transport policies and their relation to risk events will allow us to anticipate contingent and differentiating scenarios between political and social actors, as well as between the public and private sectors.

The meta-analytical technique has allowed to differentiate the literature that deals with public policies, exposure risk events and probable sequels in users, but an analysis of the trajectories of relationships between these variables will allow to observe the efficiency of the programs and the effectiveness of the strategies to reduce risks, prevent accidents and address the illnesses derived from the transfer of users from the urban periphery to the central city.

\section{Conclusion}

The aim of this paper was to carry out a meta-analysis of public transport studies in order to compare metropolitan policies in the face of risk events and their effects on users. The review highlights the emergence of acultural, poly, multi, inter and transcultural systems to the extent that public transport was designed as an instrument of rural development management in reference to the city.

\section{References}

1. A. Sánchez (2018). Categorial structure of subcategories in the exploration of press releases related to the administration of migratory security. Frontiers, 11 (28), 1-23

2. B. L. Rivera (2014). Habitus mobility around public transport. Implications for sustainable local governance. IV Regional Colloquium of Social Sciences "The contours and vicissitudes of urban development: the planning and social construction of space before the emergence of new actors. UAEM-UAPZ 12 to 14 March 2014

3. C. García (2014). Complex political systems: Implications for sustainable public security. Actions and Social Investigations, $34,1-58$
4. C. García (2015). Differences with the risk perceptual aglomerations in a public transport and concession. Iberoforum, 10 (19), 112-131

5. C. García (2015). Empirical test a model of quality of life. Civilizar, 15 (28), 181-196

6. C. García (2015). Governance of crime sociopolitical in Mexico. Papper, reflections and Analysis, 14, 47-69

7. C. García (2015). Reliability and validity of an instrument measured subjective governance. Administrative Science, 2, 143-154

8. C. García (2015). Reliability and validity of an instrument that measures criminal perceptions. Education and Development, $34,25-33$

9. C. García (2015). Reliability and validity of an instrument that measures perceptions of corruption. American Thouthg, 8 (5), 108-120

10. C. García (2015). Specification fo a communication model of environmental risk to climate change. Science, 3 (6), 71-90

11. C. García (2015). Specification of a model of criminal behavior. Psychological Research, 5 (2), 2028-2046

12. C. García (2015). The sociopolitical legitimacy of the administration of public security in Xilitla, San Luis Potosi (Mexico). Research Management, 115 (44), 24-40

13. C. García (2016). Approach to the frame of the print media regarding the attention the victims of case Ayotzinapa. IgualaGerrero (Mexico). Secci, 20 (39), 153-160

14. C. García (2016). Contrast of a model quality of life in the students of university autonomous of state of Mexico. Gerencial Vision, 15 (1), 8-43

15. C. García (2016). Governance of terror a crime. Eureka, 13 (2), 168-185

16. C. García (2016). Public security governance base on ideas on identity and risk perception that haves been established by the media within the citizens agenda. Social Work, 11 (13), 103116

17. C. García (2017). Specification a model for the study of local governance. Sinchrony, 21 (72), 459-472

18. C. García (2018). Exploratory factors structural of the habitus mobility. Interconecting Knowledge, 3 (6), 37-46

19. C. García (2018). Specified model for the study of the effects of climate change on public health. Ockham, 16 (2), 1-31

20. C. García (2018). Theory of sustainable behavior for local development.Clivajes, 5 (9), 71-94

21. C. García (2019). Dimensions of human development theory. Ehquidad, 11, 27-54

22. C. García. (2015). Reliability and validity of an instrument to measures socio-political dimensions of the quality of life. Psicumex, 5 (2),79-92

23. D. Mendoza (2017). Specification of a model representations propagandistics in ederly adults to safety publics. Tlatemoani, $25,21-30$

24. E. Martínez (2019). Governance of quality of life and wellbeing subjective. Ajayu, 7 (1), 121-139

25. E. Villegas (2018). Social Works towards a quality of life and wellbeing subjective. International Journal of Research iin Humanities and Social Studies, 5 (6), 1-14

26. F. J. Rosas (2013). Sociopolitical complexity of public transport in the State of Mexico. First Academic Encounter on 
Sustainability and Public Transport Planning. UAEMUAPNNovember 14, 2013

27. F. R. Sandoval (2018). Modelling of determinants image and destination as a subsystem periurban mobility policies. Transport of zero emissions carbon dioxide to atmosphere habitus transfer. Social Science Learning Education Journal, 3 (9), $1-4$

28. F. R. Sandoval (2018). Sociodemogrphics determinants of mobility habitus. Atlante, 9, 1-22

29. J. Carreón (2013). Sustainability of public transport. First Academic Encounter on Sustainability and Public Transport Planning. UAEM-UAPN November 14, 2013

30. J. Carreón (2013). Theories of public safety and perception of crime. Margin, 71, 1-16

31. J. Carreón (2014). Perceptual differences before the risk to the agglomerations in public transport concession. Sustainable Local Development, 7, 1-17

32. J. Carreon (2015). Administration the social fears: contrast in a model of perception of security in Mexico. Ehquidad, 4, 31-60

33. J. Carreón (2018a). Networks of violence regarding the gpovernance of public security. Social science, 4 (2), 60-65

34. J. Carreón (2018b). Reliability and validity of a model of governance of security. Frontiers, 11 (27), 1-43

35. J. Carreón. (2016). Reliability and validity of an instrument that measures seven dimensions of security perceptions in students from a public university. Journal Psychology and Behavioral, $12(20), 65-76$

36. J. Carreón. (2017). Governance of public security in the building sociopolitical identity. Psychology, 6 (12),32-52

37. J. Hernández (2014). Sociopolitical complexity of public transport. Implications for sustainable local development. Reason and Word, 86, 1-27

38. J. Hernández (2014). Tariff sustainability of public transport. Implications for local governance. IV Regional Colloquium of Social Sciences "The contours and vicissitudes of urban development: the planning and social construction of space before the emergence of new actors. UAEM-UAPZ 12 to 14 March 2014

39. M. Bustos (2019). Discussion of a theoretical review alluding to sustainable behavior and the governance of common goods. GPT, 34, 39-52

40. M. Juárez (2019). Specification of a model for the study of intercultural migration. IASF, 12 (29), 6-25

41. M. L. Morales (2013). Habitus of public transport in Edimex. First Academic Encounter on Sustainability and Public Transport Planning. UAEM-UAPN November 14, 2013

42. National Institute of Statistics, Geography and Informatics (2010). XIII National Population and Housing Census. Mexico: INEGI

43. O. Valdés (2019). Specification of a model for the study of the of the stablishment of multiple water sustainability agendas. Sinchrony, 22 (75), 281-298

44. R. Rincón (2018). Interpretation of discourses around the habitus of mobility to unveil the meaning of public transport, Margen, 90, 1-13

45. S. Mejía (2014). Sociopolitical complexity of public transport. Implications for sustainable development. IV Regional Colloquium of Social Sciences "The contours and vicissitudes of urban development: the planning and social construction of space before the emergence of new actors. UAEM-UAPZ 12 to 14 March 2014

46. S. Mejía (2016). Psychological effects of violence and insecurity in ederly. Eureka, 13 (1), 39-55

47. S. Mejía (2018). Exploratory category structure of civil mobilization in the contruction of security agenda. Frontiers, 11 (28), $1-18$

48. S. Mejía (2018). Reliability and validity of a instrument that measures the perception of the reliability penitentiary governance.Psychology, 7 (13), 80-96

49. W. I. Aldana (2018). Specification of a model for the study of the public security agenda. Atlante, 9, 1-20

50. W. I. Aldana (2019). Especificación de un modelo para el estudio de la identidad migratoria. Psychology, 30, 1-9
This work is licensed under Creative Commons Attribution 4.0 License

\section{To Submit Your Article Click Here: Submit Manuscript}

DOI: $10.31579 / 2692-9392 / 074$
Ready to submit your research? Choose Auctores and benefit from:

$>$ fast, convenient online submission

$>$ rigorous peer review by experienced research in your field

$>$ rapid publication on acceptance

$>$ authors retain copyrights

$>$ unique DOI for all articles

$>$ immediate, unrestricted online access

At Auctores, research is always in progress.

Learn more https://auctoresonline.org/journals/archives-of-medicalcase-reports-and-case-study 